Revista Mídia e Cotidiano

Artigo Seção Temática

Volume 11, Número 1, abril de 2017

Submetido em: 10/04/2017

Aprovado em: 30/04/2017

\title{
RÁDIOS COMUNITÁRIAS E DIREITOS HUMANOS. O CASO DA RÁDIO \\ SERRA FM: desafios e atitudes do fazer comunicação comunitária em um dos municípios de menor idh do país
}

\section{COMMUNITY RADIOS AND HUMAN RIGHTS. THE CASE OF RADIO SERRA FM: challenges and attitudes of doing community communication in one of the municipalities with the lowest hdi in brazil}

\author{
Orlando Maurício de Carvalho BERTI ${ }^{1}$
}

Resumo: O estudo faz uma reflexão sobre os desafios e atitudes para a promoção da comunicação comunitária e dos direitos humanos da rádio comunitária Serra FM, localizada na cidade sertaneja de São Francisco de Assis do Piauí (a 500 quilômetros da capital, Teresina). Objetiva-se: destacar, analisar, mostrar e debater o fenômeno. Parte-se de um estudo de caso, balizado também em pesquisa documental e bibliográfica, notadamente em fundamentações sobre Comunicação, Comunicação Comunitária e Direitos Humanos. Destaca-se que a emissora tem uma maneira própria de promoção de direitos humanos e que seus desafios residem principalmente em ter uma maior interação com as demandas contemporâneas.

Palavras-chave: Comunicação; Comunicação Comunitária; Direitos Humanos; Rádio Comunitária; Rádio Comunitária Serra FM.

Abstract: The study reflects over the challenges and attitudes towards the promotion of community communication and humans rights of community radio Serra FM, located in the city of São Francisco de Assis do Piaui (310 miles from the capital of state, Teresina), in the sense of its. The objective is to highlight, analyze, show and discuss the phenomenon. It is based on a case study, also focused on documentary and bibliographical research, notably on the basis of Communication, Community Communication and Human Rights. It is noteworthy that the broadcaster has its own way of promoting human rights and that its challenges lie mainly in having a greater interaction with contemporary demands.

Keywords: Communication; Community Communication; Human rights; Community Radio; Serra FM Community Radio.

\footnotetext{
1 Jornalista e militante social. Professor, pesquisador, extensionista e coordenador do curso de Comunicação Social - habilitação em Jornalismo - da UESPI (Universidade Estadual do Piauí - campus de Teresina - PI). Coordenador do Núcleo de Pesquisa em Comunicação Alternativa, Comunitária e Popular da UESPI. É doutor e mestre em Comunicação Social pela UMESP, com estágio doutoral na Universidad de Málaga (em Málaga, Espanha).E-mail: orlandoberti@yahoo.com.br.
} 


\section{míiA

Introdução

O presente estudo analisa o caso da rádio Comunitária Serra FM, município sertanejo de São Francisco de Assis do Piauí, a 500 quilômetros de Teresina, na região central piauiense, e sua relação com a promoção dos direitos humanos. O trabalho destaca o lugar de fala assumido pelos agentes sociais envolvidos nos processos comunicacionais, reconhecendo a tentativa diária de se fazer uma rádio comunitária com mais participação cidadã. Ainda que não haja, entre os comunicadores, uma reflexão sobre o que sejam realmente direitos humanos, esses direitos são refletidos e destacados quase que diariamente na programação da emissora.

Desta forma, a Serra FM traz uma contribuição importante para pensar o papel da própria comunicação comunitária e suas interfaces contemporâneas, notadamente com os direitos humanos. Partimos da compreensão de comunicação comunitária tal qual pensada por Peruzzo (1988), como aquela da, na e para as comunidades.

Ainda que nos últimos anos essa relação entre comunicação e direitos humanos tenha sido mais explorada, a temática ainda precisa ser mais estudada pela Academia, tanto em sua face teórica, quanto em sua face empírica. Parte-se de um lugar de fala no sentido da responsabilidade acadêmica, científica, social e pessoal de pensar a agir sobre os próprios territórios de origem, tentando instigar suas demandas comunicacionais. Parte-se também do lugar de fala de uma militância social em prol das rádios comunitárias do Sertão do Nordeste do Brasil e o entendimento, aclaramento e desvelamento dos seus potenciais junto aos agentes comunitários das emissoras e, principalmente, dos próprios grupos sociais em que estão inseridas.

Metodologicamente é feito um estudo de caso da rádio Serra FM. A emissora, juntamente com outras rádios da região sertaneja nordestina, faz parte de uma série de estudos que temos desenvolvido nos últimos anos. O caso da emissora vem sendo acompanhado desde 2006, destacando-se virtudes, conquistas, polêmicas e defeitos em seu trabalho. Argumentamos que a rádio atua como um canal de Comunicação Comunitária que realmente promove os direitos humanos, instigando principalmente a participação das comunidades. 


\section{míDiA

O entendimento dessa promoção, em sua história e ações, sedimenta os procedimentos metodológicos. São utilizados também a pesquisa de campo, com a realização de quase 20 visitas à emissora e à cidade de São Francisco de Assis do Piauí em um espaço de 11 anos. Promoveram-se dois cursos de extensão, documentados em mais de mil horas de gravações e entrevistas com a direção, voluntários da emissora e membros da comunidade da cidade. Baliza-se também o trabalho em pesquisa documental para o entendimento histórico do objeto. É utilizada pesquisa bibliográfica para o fortalecimento teórico do estudo, destacado principalmente as questões comunicacionais, em especial das rádios comunitárias, e ainda dos direitos humanos.

Para tornar o material mais didático ele é dividido em quatro partes. A primeira, "São Francisco de Assis do Piauí. Dos confins do Sertão às necessidades de ecos comunicacionais", trata sobre o município estudado, que é um dos que tem o menor IDH - Índice de Desenvolvimento Humano - do Brasil, no qual historiciza-se e traz-se dados sobre o lugar. A segunda parte, "A rádio Serra FM. O início do fim do silêncio em uma região historicamente quase muda às tentativas de realizar Comunicação Comunitária", fala sobre a emissora estudada em si; é trazido uma breve história da rádio, suas virtudes e questões comunicacionais que levam a uma reflexão para a resposta à problemática. No terceiro momento, "Direitos Humanos, Comunicação e Comunicação Comunitária: um debate mais que premente", são enfatizadas questões teóricas que refletem aspectos comunicacionais, comunicacionais comunitários e direitos humanos, inclusive para dar destaque às possíveis interfaces dessas áreas e a emissora estudada. A quarta e última parte, "O caso da rádio comunitária Serra FM e seus desafios e atitudes do fazer comunicação comunitária e instigar direitos humanos", destaca os pontos positivos e desafiadores do trabalho dessa emissora, que não é um caso isolado em termos de promoção de comunicação comunitária e direitos humanos no Brasil. É importante ser refletido porque tem ações desafiadoras que precisam ser conhecidas, ampliadas, melhoradas, justamente para voltarem como forma de contributo prático a essa realidade social. 
São Francisco de Assis do Piaúi. Dos confins do Sertão piauiense às necessidades de ecos comunicacionais

São Francisco de Assis do Piaú é um dos 224 municípios piauienses. Foi batizado em homenagem a seu padroeiro católico, o santo italiano Francisco de Assis (1182 1226). No Piauí quase $20 \%$ dos municípios têm nomes homenageando divindades católicas apostólicas romanas, inclusive no estado há um município quase homônimo: a também sertaneja, e mais antiga, São Francisco do Piauí, bem como também há a sertaneja Lagoa de São Francisco (o município mais pobre do Sertão Norte piauiense).

O município fica localizado a 500 quilômetros ao Sul de Teresina e só é acessível por uma única estrada asfaltada (a PI-459, já construída no Século XXI e que não dá acesso direto aos principais municípios que oferecem serviços essenciais aos sãofranciscoenses). Por isso, até o início do ano de 2017 os principais acessos rodoviários da cidade ainda eram por escassas estradas vicinais caatinga adentro.

Segundo o IBGE (2017) o município tinha uma população estimada em 5.810 pessoas, que viviam em uma área territorial de 1.100,3 quilômetros quadrados, com uma densidade populacional de 5,06 habitantes a cada quilômetro quadrado. Sua população eminentemente rural, com muitas comunidades ainda sem o fornecimento de energia elétrica. Ainda segundo o IBGE, o município registrou uma derrocada nos índices de matrículas escolares, o aumento na mortalidade infantil e a queda no Índice de Desenvolvimento da Educação Básica, indo na contramão de boa parte dos paupérrimos municípios do Sertão Nordestino.

Esses e outros dados, segundo o Atlas de Desenvolvimento Humano (2017), fizeram o município piauiense figurar com o $17^{\circ}$ pior Índice de Desenvolvimento Humano do Brasil, ocupando a 5549a posição (entre 5565), com índice de 0,485 (comparado à maioria dos países com índices sociais mais frágeis do Mundo).

Também segundo o IBGE (2017), 50,87\% de sua população é formada de homens e $49,13 \%$, de mulheres, sendo que $25,67 \%$ viviam na zona urbana e $74,33 \%$ viviam na zona rural, tornando-o um dos lugares mais rurais de todo o Sertão nordestino.

São Francisco de Assis do Piauí foi fundado em 1995 e oficialmente instalado em 1996 ao ser desmembrado da hoje vizinha Conceição do Canindé (que têm seus centros 


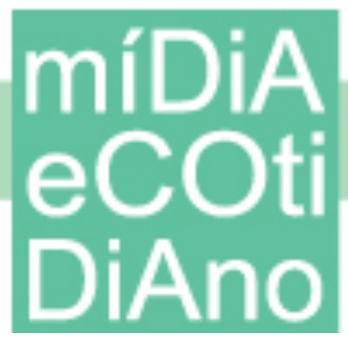

urbanos distantes em 40 quilômetros). Contemporaneamente São Francisco de Assis continua dependendo economicamente de Conceição do Canindé e de cidades do Sertão piauiense como Simplício Mendes e Paulistana (distantes respectivamente 63 e 70 quilômetros).

Comunicacionalmente o município recebe sinal televisivo apenas da TV Antena 10 (afiliada à TV Record no Piauí), oriunda da capital, Teresina. Jornais impressos não chegam regularmente ao município e as rádios regionais que são captadas em São Francisco de Assis do Piauí não têm tanta constância. Elas, quase sempre operando em AM (amplitude modulada), são oriundas das cidades de Paulistana, Simplício Mendes e até da pernambucana Petrolina (a 232 quilômetros de distância), que por muito tempo influenciaram comunicacionalmente o município em termos de notícias regionais, nacionais e internacionais.

A comunicação local e regional é feita basicamente pela Serra FM, única emissora de rádio comunitária operando em frequência modulada (FM) em um raio de quase 80 quilômetros. Essa rádio é a responsável por trazer o local e o regional aos moradores do entorno e tentar transformar essa realidade de dados econômicos e sociais tão desfavoráveis, além de instigar, esclarecer e vivenciar questões relacionadas a direitos humanos.

\section{A rádio Serra FM. O início do fim do silêncio em uma região historicamente quase muda às tentativas de realizar Comunicação Comunitária}

Fundada no final do Século passado, mas inaugurada apenas nesse Século, a rádio comunitária Serra FM tem uma série de responsabilidades, principalmente por ser o único meio de comunicação social que representa as questões locais em um raio de dezenas de quilômetros. Segundo Alain Bourdin (2001) o local está mais nas questões do pertencimento e esse pertencimento é de responsabilidade da emissora. A FM, apesar de ser comunitária, termina sendo um meio de comunicação regional. Por estar em um lugar alto seu sinal termina chegando não só às zonas urbana e rural de São Francisco de Assis do Piauí, mas também ecoa a cidades sertanejas vizinhas como Bela Vista do Piauí, Campo Alegre do Fidalgo, Conceição do Canindé, Jacobina do Piauí, Lagoa do Barro do 
Piauí, Paulistana e Queimada Nova, sendo o único meio de comunicação para envio de avisos e reflexões sociais também em boa parte das zonas rurais desses municípios sertanejos piauienses.

A Serra FM tem esse nome devido estar em uma região cercada por morros, também conhecidos por serras na região sertaneja brasileira. Sua sede urbana fica a 415 metros de altitude em uma área eminentemente árida e com fortes complicações ao acesso a água e políticas públicas.

A sede do município só veio ter fornecimento regular de água no final da primeira década do Século XXI. São Francisco de Assis em sua zona rural sofre em pleno final da segunda década deste século com questões de acesso ao precioso líquido. Os poucos poços e barragens construídas às vezes secam durante os períodos de estiagem ou então terminam tendo água contaminada ou salobra o que gera uma quase dependência de sistemas de carros-pipa.

A conjuntura da água, das questões sociais, do acesso a políticas públicas básicas e também da premência educacional são direitos humanos básicos que circundam as questões da programação da Serra FM.

A emissora foi fundada em 1998, no segundo ano de existência da cidade. Na época os equipamentos foram comprados pelos administradores públicos da cidade, entusiastas de sistemas de radiodifusão. Outro ponto premente da fundação da Serra FM era que a emissora ajudaria a tira-la do isolamento geográfico, como um meio comunicacional para mobilizar a população do município, que tem localidades distantes quase 40 quilômetros e com capilaridade via estradas de deslocamentos que ultrapassam as três horas.

A fundação da emissora, portanto, pretendeu desenmudecer a região. Por muitos anos operou no sistema de divulgação de políticas públicas na cidade e também da tentativa de interligação entre as zonas urbana e rural.

Ela é mantida pela Associação de Rádio Comunitária de São Francisco de Assis e os recursos que cobrem parte de suas despesas advêm de ajuda dos membros do Clube do Ouvinte da emissora. Também recebe ajudas pontuais de comerciantes, moradores da cidade e de imigrantes que residem nos principais centros urbanos do país e que reconhecem o trabalho da rádio. 
A ajuda dos poderes públicos oscila pelo humor dos administradores para com a rádio e também das sobras de despesas, nem sempre presentes. Não há oficialmente um apoio à rádio e todo o seu corpo de dez voluntários não é remunerado. Vez por outra, quando sobram recursos, são divididos entre os voluntários.

Todos os comunicadores da emissora têm outras profissões e utilizam essa função para realizar o sonho de comunicar e tentar contribuir para melhoria do município. Alguns dos radialistas da Serra FM são agricultores, outros, funcionários públicos municipais e estaduais, outros, comerciantes e alguns são líderes de igrejas, oriundos de vários lugares do município, credos religiosos e ideologias político-partidárias.

A Serra FM teve legalização definitiva em 2007, três anos depois de conseguir concorrer e se habilitar a operar um canal de rádio comunitária na região. Foi uma das primeiras emissoras de rádio comunitária do Sertão do Piauí a ser legalizada. Em trabalho de nossa autoria (2009, p. 222) frisávamos que São Francisco de Assis do Piauí era uma cidade em que pouca parte da população tinha acesso ao fornecimento de energia elétrica e a bens como TV (sendo que era quase toda captada por antenas parabólicas). "Uma emissora local de rádio pode ajudar no redentorismo e ajudar no desenvolvimento da região" (BERTI, 2009, p. 222).

Até o final do primeiro trimestre de 2017, a Serra FM tinha programação diária de mais de 12 horas, com conteúdo quase todo local, eminentemente musical, mas sempre aberto à participação da população em todos os horários, inclusive nos que estavam fora do ar. Funcionava na frequência $87,9 \mathrm{MHz}$.

A emissora também está na Internet, no endereço www.radioserrafm87.com. A Serra FM conta com espaços de interatividade. A rádio ainda está presente em redes sociais virtuais, principalmente no Facebook (https://www.facebook.com/serrafm879) onde mantém constante diálogo com ouvintes e usuários.

Nota-se que ao estudar-se a rádio e seu trabalho por, aproximadamente, 11 anos (BERTI, 2009 e 2014), destaca-se que ela instiga a participação da população, mas na maneira particular de entender o que é esse ato social. Destaca-se também que seus membros são sempre abertos ao conhecimento e muito interessados em aprender, seja via cursos presenciais ou online. Quase a totalidade dos comunicadores da emissora tinham 
o ensino médio, mas eram dotados de garra a aprender e, quando havia funcionamento de Internet na cidade, sempre estavam buscando em sites especializados e redes sociais informações que pudessem trazer melhores dias a São Francisco de Assis do Piauí e região.

Em que e como esse trabalho reflete as questões dos direitos humanos em uma das regiões mais pobres e socialmente vulneráveis do Brasil?

\section{Direitos Humanos, Comunicação e Comunicação Comunitária: um debate mais que prementes}

Inicialmente soa preconceituosa a afirmação de que há lugares com maior ou menor discussão sobre direitos humanos. Em um Brasil continental, mais que multifacetado em suas identidades, conceitos, preconceitos e divisões sociais, o debate acerca das temáticas de direitos humanos e sociais é mais que necessário.

Mas será que a Sociedade, e respectivamente as comunidades, querem debater isso? E por que não debatem? Qual o papel dos meios de Comunicação Social nesse processo? E os meios comunitários?

Esse debate é recente. No Brasil em que há os paradoxos da discussão da tal Pósverdade (as várias verdades e suas diversas interpretações) em ambientes tidos como antenados e desenvolvidos, há outros lugares que ainda lutam apenas para terem energia elétrica e o fornecimento de água ou até de terem acesso a água de qualidade.

O próprio entendimento e vivência sobre direitos passa por debates e interpretações diferentes. Até mesmo na própria cidade esse debate termina sendo dual dependendo do lugar em que ele está sendo feito. Esse é o Brasil de vários brasis.

Mas o que são direitos humanos e o que eles têm com a Comunicação? São consonantes, dissonantes e em que pontos podem atuar em prol da própria coletividade, objetivo central da defesa de quaisquer direitos.

Parte-se da noção de direitos humanos, como destaca Fábio Konder Comparato (2010, p. 80-81), no sentido de garantir, via acordos, leis fundamentais, constituições, declarações de efeito obrigatório e tratados internacionais que já entraram em vigor para 
garantir direitos civis e políticos, além de direitos econômicos, sociais e culturais a par do reconhecimento de novos direitos humanos.

Eduardo Rabenhorst (2014, p.02) enfatiza que direitos partem a partir do que é reto, correto ou justo, bem como é a possibilidade de exigir uma conduta dos outros, tanto uma ação, quanto omissão e que os direitos humanos "são os direitos correspondentes à dignidade dos seres humanos" (RABENHORST, 2014, p.04).

Esses direitos, humanos e sociais, são interconectados com a Comunicação a partir de que as vivências comunicacionais têm forte poder de mediar os próprios direitos humanos. "Todos os seres humanos nascem livres e iguais em dignidade e em direitos. Dotados de razão e de consciência, devem agir uns para com os outros em espírito de fraternidade" (DECLARAÇÃO, 2017, p. 02). O documento reflete as questões sobre as garantias jurídicas universais no sentido de proteger os seres humanos e grupos contra omissões e ações dos governos que atentem contra a dignidade humana. "A dignidade é o valor que atribuímos aos seres humanos em função das nossas crenças sobre o modo como os mesmos devem ser tratados" (RABENHORST, 2014, p. 07)

Segundo a Rede Nacional de Adolescentes e Jovens Comunicadores (2017) o direito à comunicação é pilar central das sociedades democráticas, significando o assumir a comunicação como direito humano no reconhecimento dos direitos de todas as pessoas a terem voz e expressão, significando também o reconhecimento da comunicação como direito universal e indissociável de todos os outros direitos fundamentais, de maneira independente frente aos meios de comunicação. É muito mais que liberdade de expressão e direito à informação. "É o direito de todas as pessoas de ter acesso aos meios de produção e veiculação de informação, de possuir condições técnicas e materiais para ouvir e ser ouvida, de ter o conhecimento necessário para estabelecer uma relação autônoma" (REDE, 2017).

Os direitos humanos também terminam sendo imbricados nas questões da cidadania. Para Norberto Guarinello (2008, p. 34) a identidade comunitária é um dos pontos que instigam a cidadania. Essa identidade foi construída ao longo do tempo a partir de populações muitas vezes díspares, sem unidades étnicas ou raciais. Elas foram criadas e recriadas, reforçadas e mantidas por mecanismos que produziram "o cidadão ao mesmo 


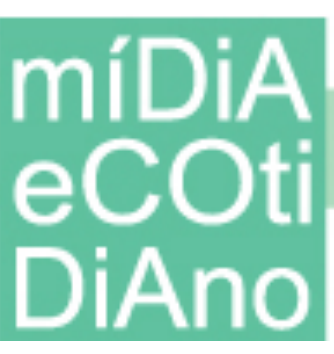

tempo em que faziam nascer cultos comuns, moeda cívica, língua, leis, costumes coletivos" (GUARINELLO, 2008, p. 38).

Um dos pontos-chave dos direitos humanos está no próprio diálogo, como frisa Paulo Freire (1987, p. 78-79). Dialogar é o encontro dos seres humanos "mediatizados pelo mundo, para pronunciá-lo, não se esgotando, portanto, na relação eu-tu". Sendo que esta razão explica os motivos de que não é possível o diálogo entre os que querem a pronúncia do mundo e os que não a querem; entre os que negam aos demais o direito de dizer a palavra e os que se acham negados deste direito. "É preciso primeiro que, os que assim encontram negados no direito primordial de dizer a palavra, reconquistem esse direito, proibindo que este assalto desumanizante continue" (FREIRE, 1987, p. 79). Sendo que é dizendo a palavra a partir da qual é pronunciando o mundo que os seres humanos transformam o diálogo, construindo o caminho pelo qual se solidarizam e refletem o agir de seus sujeitos.

Todas essas questões refletem também o direito humano à comunicação, a poder ouvir e ser ouvido. É o que Ilana Polistchuck e Aluízio Trinta (2003) chamam de modelo horizontal da informação, em que os sujeitos do processo comunicacional, emissor e receptor, têm o mesmo protagonismo na comunicação. É a tônica da máxima do poder ser ouvido, em vez de poder só receber mensagens "de cima".

Esse pensamento se afina com o artigo 19 da Declaração Universal dos Direitos Humanos (2017) em que "[...] todo indivíduo tem direito à liberdade de opinião e de expressão; este direito inclui a liberdade de, sem interferência, ter opiniões e de procurar, receber e transmitir informações e ideias por quaisquer meios, independentemente de fronteiras".

Esses pensamentos estão no próprio conceito de comunicação comunitária, como frisa Cicilia Peruzzo (1998), enfatizando a promoção de melhorias. Uma delas é a garantia dos direitos básicos. 
O caso da rádio comunitária Serra FM e seus desafios e atitudes do fazer comunicação comunitária e instigar direitos humanos

As questões dos direitos humanos estão ligadas diretamente com as práticas e vivências da cidadania. Uma não pode andar sem a outra e o entendimento e vivência de apenas uma dessas interfaces pode ser o sinal que está havendo abandono de iniciativas ou até descomunitarização.

Encontra-se na Serra FM, da cidade de São Francisco de Assis do Piauí, uma cidadania voltada para questões sociais e comunitaristas. Os ambientes formais de ensino pouco têm debatido a temática na cidade e o meio de comunicação e as instituições religiosas (outros ambientes formadores no município) terminam por ter como pontos principais de pauta questões básicas de sobrevivência. Parte-se da questão que antes dos debates vem a subsistência.

A reflexão também de que as questões básicas de vida são direitos humanos e sociais são desafios do dia-a-dia da emissora e das próprias organizações sociais sãofranciscoenses. Pontos nevrálgicos que não são exclusividades do lugar, mas quase endêmicas no Sertão Nordestino brasileiro.

O grande nível de analfabetismo e analfabetismo funcional do lugar fazem que as instituições formais de conhecimento não sejam as únicas instituições formativas da região. A emissora de rádio comunitária termina por ser o lugar convergente para o debate sobre os direitos humanos e cidadania.

Dezenas de anos de opressão social e da falta de políticas públicas básicas levaram a maioria da população da região estudada a sequer ter conhecimento dos seus direitos básicos. Era uma população quase totalmente emudecida e oprimida. A "ascensão" econômica de parte da população, que saiu da linha abaixo da pobreza e passou a ser considerada pobre, trouxe não apenas alimentação básica para a mesa, mas a consciência (e até cobrança) de um Estado mais presente. A emissora comunitária foi ponto-chave nessa evolução, pois ajudou a multiplicar o que antes já tinha sido começado na forma de comunicação mais popular: o boca a boca.

Um ponto a ser levado em conta é que mesmo com o desconhecimento conceitual de cidadania e direitos humanos, eles passaram a ser divulgados e exigidos na emissora e 
terminaram reverberando na população, que somente no Século XXI ganhou sua primeira (e até o final do primeiro terço de 2017, única) escola de ensino médio.

Esse debate pode ser visto a partir do espaço aberto pela rádio não só para participação básica - como o envio de "alôs" ou "abraços", além de pedidos de músicas -, mas também para o intercâmbio de informações, cobrança e reflexão sobre atos dos poderes públicos. Nota-se que nos mais de dez anos de acompanhamento da emissora há uma evolução nessas questões.

Instigar a participação também é ponto para promover os direitos humanos, para refleti-los e para fazer, principalmente as camadas sociais historicamente alijadas, a terem maior empoderamento social frente as questões. Em se tratando de São Francisco de Assis e região, são pontos mais prementes, já que as violações contra direitos humanos e direitos básicos mais são corriqueiras.

A rádio Serra sai de um status puramente regional e local para ser o único meio integrativo, transpassando unicamente as questões geográficas para tentar instigar perspectivas sociais.

A FM faz um trabalho não só assistencialista ao promover campanhas beneficentes para membros da comunidade que necessitam tratamento fora do município ou de trabalhos para ajudar moradores carentes, mas também trazendo noticiários e reflexões sociais.

São Francisco de Assis do Piauí tem uma questão diferencial que é o trabalho da Fraternidade São Francisco, ligada diretamente à Igreja Católica. A entidade termina sendo um braço social e político que tenta transformar a região em um lugar mais justo e irmanado. O trabalho da Fraternidade é mais ágil e efetivo do que dos próprios poderes públicos. Essa atuação é refletida principalmente a partir de que há um trabalho dos agentes pastorais, espécie de mediadores sociais entre a Fraternidade e as comunidades da cidade de São Francisco de Assis do Piauí, como é destacado em BERTI (2009 e 2014). No entanto, mesmo a cidade sendo eminentemente católica há uma pluralidade religiosa na emissora, como foi constatado por Hosana Tenório dos Anjos (2014).

Nota-se que em um lugar ainda isolado geográfica, e quase totalmente no sentido comunicacional, que demandas de direitos humanos terminam sendo a garantia de direitos 
básicos e que os direitos humanos considerados como contemporâneos e mais atualizados nos grandes centros, são conhecidos sim, mas ainda distantes, justamente porque os mesmos direitos básicos terminam não sendo respeitados.

O trabalho da emissora comunitária serve justamente para refletir e promover esses direitos, mesmo não havendo uma sistematização e uma constância diária.

Em termos de programação a emissora não tem uma camisa de força como parte da mídia-hegemônica em que seus programas têm de cumprir rigorosamente horários por causa dos anúncios comerciais. Na Serra FM há horários flexíveis sobre conteúdos e se há alguma entrevista premente ou então a visita de alguém que possa dar esclarecimentos sobre quaisquer assuntos de interesse comunitário, a programação é interrompida para que possam ser dados os avisos e a pessoa que veio falar possa interagir com os ouvintes. Um dos pontos interessantes é que essa interação ocorre de diversas maneiras: desde o tradicional bilhete, enviado pelos moradores da zona urbana e das comunidades próximas, que se dirigem à rádio em momentos de entrevista. Ou então após entrevistas para mais esclarecimentos e cobranças, via ligações para os telefones fixos e móveis da emissora, bem como pelo envio de mensagens pelo espaço no site da rádio e até por mensagens instantâneas via Facebook, pelo aplicativo de mensagens Whatsapp e também por SMS. Nota-se que esse sistema funciona bem e aproxima vários moradores do trabalho da Serra FM.

Agora dizer que é uma revolução participativa ainda é um ponto a ser refletido já que muitas das mensagens tratam de pedidos de músicas ou de perguntas básicas. O que não deixa de ser uma evolução de participação.

Nota-se que ainda há vergonha de realização de indagações mais esclarecedoras, principalmente quando há o confronto aos poderes públicos constituídos, principalmente o municipal. Ainda impera em parte da população o receio à crítica desses poderes, como se os mesmos pudessem prejudica-los através de represálias. Infelizmente é um fato no Sertão nordestino brasileiro represálias e perseguições políticas, bem ao estilo coronelístico, de quem realmente discorda dos mandatários locais.

Em relação a São Francisco de Assis do Piauí nota-se, em toda quase uma década de acompanhamento "in loco" da emissora, que essa perseguição não ocorre de maneira 
direta, mas a auto-censura de parte dos moradores é alimentada pelo receio das perseguições, restringindo a participação mais diretas e efetiva em relação às cobranças aos poderes públicos constituídos.

Destaca-se, também, sempre nos 11 anos em que estuda-se o caso da emissora, que as temáticas, caso provocadas, terminam sendo elencadas nos microfones e participação da rádio. Mas que não há uma cultura, nem local nem comunicacional, de estímulo ao debate constante.

Por isso destaca-se que uma das carências do trabalho não está na falta de vontade dos comunicadores ou comunidades, mas de um trabalho educacional maior, inclusive que poderia ser feito pela única unidade de ensino médio da região, Unidade Escolar Professor Vicente Gualberto Ribeiro.

\section{Considerações finais}

Direitos humanos e direitos sociais caminham juntos no sentido de trazerem pistas e respostas para melhorias sociais. Infelizmente o estado de mudez de boa parte das populações historicamente alijadas nos leva a concluir que ainda estamos distantes da construção de um modelo de comunicação que coloque na pauta diária as discussões sociais. Muitas vezes comer, ter energia elétrica e água em casa são questões mais prementes, apesar de serem direitos humanos básicos. O desafio não é importante apenas para a rádio Serra FM mas também para todas as emissoras de rádio comunitária do País.

Será que os níveis de debate e reflexão sobre direitos humanos estão a contento? As populações dessas comunidades se sentem representadas por suas emissoras? E até que ponto coletivamente essas rádios e outros meios de comunicação comunitários têm se diferenciado dos demais, notadamente em relação a uma atividade contra-hegemônica e participativa?

As respostas podem não ser completas e haver mais hiatos no processo, mas elas precisam ser buscadas e transformadas em ações. A reflexão sobre as questões comunicacionais verdadeiramente sociais, podem levar a sociedade a respeitar e honrar os direitos humanos e suas violações diminuídas. 
Cabe também a Academia, no tripé ensino, pesquisa e extensão, a instigar e a vivenciar mais esses processos, entendê-los junto às comunidades e trazer mais elementos para reflexão. Não adianta só teorizar, mas também vivenciar a prática, instigá-la e respeita-la e tentar aprender com os trabalhos desses agentes sociais para intercambiar conhecimentos.

Por mais rádios Serras e por melhorias em São Francisco de Assis do Piauí e de todo o Sertão. Quiçá com muito mais consciência de ações sobre direitos humanos, tão combatidos em período de temeridade e perda de tantos direitos sociais, mesmo nos lugares que já suplantaram o conhecimento acerca dos direitos sociais básicos e já avançaram nas discussões e práticas da defesa de direitos humanos.

\section{Referências}

ANJOS, Hosana Tenório dos. A participação da comunidade da cidade de São Francisco de Assis do Piauí, no Sertão Piauiense, na rádio comunitária Serra FM. Monografia (Trabalho de Conclusão de Curso em Comunicação Social - habilitação em Jornalismo) - Universidade Estadual do Piauí: Picos, 2014.

ATLAS BRASIL. Atlas de Desenvolvimento Humano do Brasil. Disponível em: $<$ http://www.atlasbrasil.org.br>. Acesso em: 19.mar.2017.

BERTI, Orlando Maurício de Carvalho. Os processos comunicacionais nas rádios comunitárias legalizadas do Sertão do Piaúi. Dissertação (Mestrado em Comunicação Social) - Universidade Metodista de São Paulo: São Bernardo do Campo, 2009.

Processos comunicacionais nas rádios comunitárias do Sertão do Nordeste brasileiro na internet. Tese (Doutorado em Comunicação Social) - Universidade Metodista de São Paulo: São Bernardo do Campo, 2014.

BOURDIN, Alain. A questão local. Rio de Janeiro: DP\&A, 2001.

COMPARATO, Fábio Konder. A afirmação histórica dos direitos humanos. São Paulo: Saraiva, 2010.

DECLARAÇÃO UNIVERSAL DOS DIREITOS HUMANOS. Artigos $\mathbf{1}^{\circ}$ e 19. Disponível em: $<$ http://www.ohchr.org/EN/UDHR/Documents/UDHR_Translations/por.pdf $>$. Acesso em: 01.abr.2017.

FREIRE, Paulo. Pedagogia do Oprimido. Rio de Janeiro: Paz \& Terra, 1987.

GUARINELLO, Norberto Luiz. Cidades-Estado na Antiguidade Clássica. In: PINSKY, Carla Bassanezi; PINSKY, Jaime. História da Cidadania. São Paulo: Contexto, 2008.

IBGE - INSTITUTO BRASILEIRO DE GEOGRAFIA E ESTATÍSTICA. Dados populacionais e históricos da cidade de São Francisco de Assis do Piauí. Disponível em: $<$ http://www.cidades.ibge.gov.br/v3/cidades/municipio/2209658>. Acesso em: 18.mar.2017. 
PERUZZO, Cicilia Maria Krohling. Comunicação nos movimentos populares: a participação na construção da cidadania. Petrópolis: Vozes, 1998.

POLISTCHUCK, Ilana; TRINTA, Aluizio Ramos. Teorias da comunicação: o pensamento e a prática da Comunicação Social. Rio de Janeiro: Campus, 2003.

RÁDIO SERRA FM. Histórico, contemporaneidade e informações sobre a emissora. Disponível em: <http://www.radioserrafm87.com>. Acesso em: 20.mar.2017.

RABENHORST, Eduardo R. O que são direitos humanos? Direitos Humanos Net, 2014. Disponível

em:

$<$ http://www.dhnet.org.br/dados/cursos/edh/redh/01/01_rabenhorst_oqs_dh.pdf $>$. Acesso em: 29.mar.2017.

REDE NACIONAL DE ADOLESCENTES E JOVENS COMUNICADORES. Direito Humano à Comunicação. Disponível em: $<$ http://renajoc.org.br/direito-humano-a-comunicacao $>$. Acesso em: 01.abr.2017. 